\title{
Artificial intelligence for fashion, Leanne Luce, Apress 2019, ISBN 978-1-4842-3930-8 how Al is revolutionizing the fashion industry
}

\section{Grace Buttler ${ }^{1}$}

Received: 6 October 2021 / Accepted: 7 October 2021 / Published online: 26 October 2021 (c) The Author(s), under exclusive licence to Springer Science+Business Media, LLC, part of Springer Nature 2021

This book is set out to be a resource to help people in the fashion industry move into using artificial intelligence in their businesses. The author, Leanne Luce, started out as a fashion designer and then moved into software and AI.

Artificial Intelligence for Fashion: How AI is Revolutionizing the Fashion Industry is an engaging and well constructed book, which takes you through the different ways artificial intelligence can be used to aid and evolve the fashion industry. The diagrams and images throughout help to explain some of the more abstract concepts, and are very useful to show how AI works if you previously haven't worked with it before. The use of a case study (a fictional fashion brand called Betty and Ruth) throughout the book helps to solidify the abstract ideas and allows the reader to see how the different types of AI would be handled in the real world.

The book is very easy to understand and starts off by acknowledging that most people don't have the technical knowledge to follow complex artificial intelligence ideas. One of the main ways that it guides you through the uses of AI, is to have real-world comparisons that are easy to relate to (such as the sewing comparison on page 5). There are clear diagrams and images throughout which help to explain the new concepts (such as the diagram on page 109 illustrating what predictive analytics are). This was especially helpful for some of the more complex ideas, where a simple image provided a clear visual aid to the text. Throughout the book Betty and Ruth (the fictional case study fashion brand) was used to show how each of the AI techniques could be applied in a real world setting, putting the computing into a context the reader is more likely to be familiar with. After each of the chapter sub-headings there was a quote from a well known figure (both in the world of fashion and technology from Coco Chanel on page 67 to Tim Berners-Lee on page 97) and this provided a touch of familiarity and warmth throughout. The book covers a

Grace Buttler

grace.buttler@outlook.com

1 London, UK 
very wide range of the fashion industry, looking at many different sectors including manufacture, photography, shopping (both online and in-store), design, trends and inspiration. Another way it makes the complex ideas surrounding AI more accessible is using everyday examples (such as challenging the science fiction version of AI with the real-world applications in chapter 11 "Robotics and Manufacturing"). Throughout the book, the use of terminology develops and builds, so by the final chapter the reader has a good knowledge of terms, but the journey to get there isn't too overwhelming.

There are lots of different examples and diagrams to explain aspects of AI (such as neural networks in chapter 4), and links to a few examples in the fashion industry. However, I would have liked a little more focus on real case studies, using sites and businesses that are more commonly known to the general public.

The layout of the book was very user friendly, and I found it easy to read and follow. I liked that all of the bigger chapters were split into smaller sections, with lots of sub headings to help guide the reader. One particular aspect that I found useful was the summary at the end of each chapter, which allows the consolidation of knowledge and ensures that everything was understood. The bibliographies throughout the book (and the longer one at the end on page 197) were also very useful for anyone who was interested in taking their learning further, and because they occurred throughout the book the reader could explore these topics as soon as a chapter had ended. I also found the bold words throughout the chapters particularly useful, as they were all listed in the 'Terminology in this Chapter' section at the end of each chapter, and this allowed me to easily look up definitions whilst I was reading.

This book is for someone with no prior knowledge of AI and programming, but knows something about, or works in, fashion and the fashion industry. It would be incredibly useful if you wanted an overview of how to start implementing some of these ideas into your company. I also think that many of these ideas and concepts would be applicable to anyone starting any sort of business or charity, and provides a perfect springboard to launch your learning.

Overall Artificial Intelligence for Fashion is very well written and kept me interested throughout. The way that new concepts and ideas were introduced challenged me, but they were delivered in such a way that I stayed engaged, and inspired me to want to do some wider reading around certain subjects.

Publisher's Note Springer Nature remains neutral with regard to jurisdictional claims in published maps and institutional affiliations. 